American Journal of Applied Sciences 7 (8): 1182-1189, 2010

ISSN 1546-9239

(C) 2010 Science Publications

\title{
Implementation of 5S Practices in the Manufacturing Companies: A Case Study
}

\author{
Mohd Nizam Ab Rahman, Nor Kamaliana Khamis, Rosmaizura Mohd Zain, \\ Baba Md Deros and Wan Hasrulnizzam Wan Mahmood \\ Department of Mechanical and Materials Engineering, \\ Faculty of Engineering and Built Environment, University Kebangsaan Malaysia, \\ 43600 Bangi, Selangor, Malaysia
}

\begin{abstract}
Problem statement: 5S practice is one of the techniques to improve quality environment, health and safety at the workplace. Evaluation of $5 \mathrm{~S}$ practice can be done through implementation of 5S audit at each division in the company. Approach: Through 5S audit, it enables each company to identify the potential level of quality improvement and at the same time can analyze their ability and weakness of each division in the company. Therefore, in order to assess the implementation of $5 \mathrm{~S}$ practice, two manufacturing companies were involved in this study. Results: The study started with understanding background of the company, recognizing divisions to be assessed in the company and come out with the complete $5 \mathrm{~S}$ checklist for each division for auditing process. Based on the result, both companies basically perform an excellent $5 \mathrm{~S}$ practice, but there are a few weaknesses that still need to be considered such as arrangement of the documents, tool and equipment. Conclusion/Recommendations: Moreover, both companies agreed that the 5S practice is seen as an effective technique that can improve housekeeping, environmental performance, health and safety standards in their workplace. However, effort and participation from top management is a key factor that determines the success of the $5 \mathrm{~S}$ practice.
\end{abstract}

Key words: 5S, checklist, manufacturing

\section{INTRODUCTION}

In recent years, the practice of $5 \mathrm{~S}$ is commonly used among the Japanese firms in order to enhance human capability and productivity. Since it was introduced by Takashi Osada in the early 1980s, it is believed that applying the $5 \mathrm{~S}$ techniques could considerably raise the environmental performance in production line including housekeeping, health, safety and more. The $5 \mathrm{~S}$ is the acronym of five Japanese words which stands for seiri (organization), seiton (neatness), seiso (cleanliness), seiketsu (standardization) and shitsuke (discipline) (Ho et al., 1995; Ho, 1997; Sui-Pheng and Khoo, 2001). Organizing the $5 \mathrm{~S}$ team is an important approach in solving many potential problems. In the other hand, the $5 \mathrm{~S}$ practice is a technique used to establish; maintain quality environment in an organization effectively and promised the employees to be more self-discipline (Ho, 1999a; Pheng, 2001).

Moreover, Ho (1999b) found that most of operating companies in Hong Kong has successfully improved quality of product as well as increasing the working life underneath of $5 \mathrm{~S}$ deployment. The $5 \mathrm{~S}$ concept is applicable for many industry types or business natures, including service sectors. In their studies, Ho et al. (1995) cited that 5S has a significant contribution to the successful of Total Quality Management (TQM) implementation, for example; in the United Kingdom, there are 205 manufacturing and 106 services companies and 16 leading companies from Japan become an important base in implementing TQM successfully.

In their studies, Ho and Fung (1994) stated that 5S is one of the strongest tools for enhancing the success factor of TQM implementation. As supported by Khanna (2009), 5S is the driver for the successful of TQM implementation and other quality tool applications. Furthermore, O’hEocha (2000) confirmed that $5 \mathrm{~S}$ is an effective technique that can improve housekeeping, environmental performance, as well as safety standards in a systematic way. However, Warwood and Knowles (2004) stated that the implementation of $5 \mathrm{~S}$ is tended to depend on the stage

Corresponding Author: Mohd Nizam Ab Rahman, Department of Mechanical and Materials Engineering,

Faculty of Engineering and Built Environment, University Kebangsaan Malaysia, 43600 Bangi, Selangor, Malaysia Tel: +603 89216449 Fax: +603 89259659 
of the $5 \mathrm{~S}$ programme. Most Japanese companies claimed that the $5 \mathrm{~S}$ benefit is not only for improving their physical environment, but also improving their thinking processes as well.

$\mathrm{Up}$ to now, $5 \mathrm{~S}$ audit could be categorized as a crucial tool to ensure that the accurate deployment of $5 \mathrm{~S}$ in an organization (Ho, 1999b). Through the audit process of the study place, it enables each organization to identify the potential level of quality improvement in real situation. According to this, the audit process (including internal or external audit) can continuously monitor the $5 \mathrm{~S}$ deployment and suggested to properly implementation. However, the $5 \mathrm{~S}$ auditing criteria must be relevant to the business nature or working environment, as well as align with organization policy and vision. In Malaysia, the Standards and Industrial Research Institute of Malaysia or SIRIM has played an effective role to encourage the utilization $5 \mathrm{~S}$ concept among Malaysian industries (Ho et al., 1995). Therefore, further studies or works being carried out continuously in order to identify, examine and develop a $5 \mathrm{~S}$ checklist in Malaysia. For example, the development of SIRIMEX model (Hamzah and Ho, 1994), SMET model (Idris et al., 1997) and TQMEX model (Ho, 1997) will able to addresses a gradually activity for company towards TQM implementation.

This study concentrates on the results of the case studies carried out as part of a research project in developing and evaluating the checklist audit for the $5 \mathrm{~S}$ practice in two manufacturing companies. Regardless of the difficulties faced in conducting the case studies, the study was successfully completed. This study is presented as follows: the first part discusses the literature review on the $5 \mathrm{~S}$; the second part gives a description of the research methodology employed in gaining the relevant information and the third part presents the case studies which based on three main areas which are: the background of the companies; the results of the implementation of the $5 \mathrm{~S}$ activity and; suggestion to improve 5S implementation at the company.

\section{MATERIALS AND METHODS}

One of the main difficulties encountered by most empirical researchers is in designing a reliable and suitable questionnaire to collect information from the sample of a population. It must allow consistent understanding by respondents and the response task or direction should be one which provides meaningful information about what respondents have to say in their response. According to this study, the questionnaires were developed based on all $5 \mathrm{~S}$ requirements and practices in the two case companies. Throughout questionnaires construction, discussions were held with the research team, to check on clarity of the questions and the appropriateness of the proposed scale. Pre test of questionnaire was conducted on two managers in a selected private company. The comments and feedback given were very useful in enhancing, rectifying and improving the questionnaire.

Generally, all the staff levels will eventually get involved in the audit process. In order to achieve the objective, several steps have been taken as follows:

- Interviewing the two selected case study companies

- Observing in the two different industry areas

- Developing the $5 \mathrm{~S}$ checklist based on the two industries

- Conducting the audit process by taking into consideration the industries' housekeeping, environmental performance and health and safety

- Analyzing the checklist record

Furthermore, there are two ranking systems utilized in this study for analyzing the condition of the companies and the details are outlined below.

- The Likert Scale is used in this study for the $5 \mathrm{~S}$ checklist to determine the level of $5 \mathrm{~S}$ practice. Several sectors/areas in the case study companies have been ranked by using this system. The cumulative value is then obtained from the total value of the items in each sector. This value obtained is then converted into percentage values. Respondents of the company were asked to indicate (by a tick) whether certain items were applicable to their companies. Most of the questions asked the respondents to rate their level of agreement to certain statements on a five point Likert scale. For example, with 5 being the highest (indicating greater agreement) and 1 the lowest, indicating lesser agreement or totally disagree

- Table 1 shows the value in percentage in order to determine the level of the implementation of $5 \mathrm{~S}$ activity in both companies and to assist these companies in recognizing the areas that need to be improved

\begin{tabular}{ll} 
Table 1: Percentage system & \\
\hline Scale of marking (\%) & Implementation's level \\
\hline $90-100$ & Excellent \\
$80-89$ & Very good \\
$65-79$ & Good \\
$51-64$ & Moderate \\
$0-50$ & Weak \\
\hline
\end{tabular}


For purposes of illustration, the backgrounds of the two companies are presented here. To maintain confidentially, the names of the companies have not been disclosed and therefore referred to as companies A and B. Basically, both the companies are considered as a medium scale industries in Malaysia.

Company A: Company A is a medium scale Japanese company and has been established in Malaysia since April 1980. Company A is a leading of global supplier in advanced automotive technology, systems and components. Company A's fundamental mission is to achieve customer satisfaction through quality products and services maintained by experienced employees. The main customers of this company are local automotive industries which are Proton and Perodua and the other multinational automotive industries like Toyota Motor Sdn. Bhd., Suzuki Malaysia Sdn. Bhd., Ford Malaysia Sdn. Bhd, Daihatsu Malaysia Sdn. Bhd. and Honda Malaysia Sdn. Bhd. Company A, associates itself with continuously consistent quality and efforts on selecting and implementing improvements that have the greatest impact on its key business plans and goals. It always focuses on achieving high quality and productivity by optimizing product designs and reducing waste and implementing variation in its manufacturing processes. Company A has been awarded the ISO/TS 16949 by the SIRIM and International Automotive Task Force (IATF), one of the bodies that represent carmakers and suppliers worldwide. It has also been awarded certification for the ISO 14001 Environmental Management System, which recognizes its commitment and efforts in maintaining the environment.

Company B: Company B was established on 17 March 1975 as a joint venture project between Malaysian and Japanese partnership and granted pioneer status for the manufacture of flexible light packaging materials. Several years ago, the ownership of this company has been changed due to the business culture. Since its inception, this company has led the local converting industry by being listed on Kuala Lumpur Stock Exchange in 1990 and obtained SIRIM's certification of its ISO 9001 Quality Management System in 1996 and ISO 140001 Environmental Management System in 2000. Its vision is to become a number one ASEAN company for quality, cost and delivery in parallel with its mission, which is to be a total package solution provider. Besides manufacturing conventional packaging products, company $\mathrm{B}$ produces special application packaging for medical, pharmaceutical, seasonings and electronic industries. As part of the company's commitment to environmental protection and corporate social responsibility, it changed its waste water treatment system in 2002 to one using "cleaner technology".

\section{RESULTS}

Company A: Figure 1 indicates the percentage value of the $5 \mathrm{~S}$ implementation at company $\mathrm{A}$ in six areas. Based on the result, only two areas were found to be out of the excellent condition.

Surrounding area: Implementation of $5 \mathrm{~S}$ activity at surrounding area in company A shows an excellent result. For company $A$, it can be deduced that an external image expresses the internal condition of the company. Since the start of this company, it has rarely faced any problems with parking, managing the security and the landscape. For this reason, an observation regarding its landscape, parking lots, warning signs, security/guard house and signboard of the company has been created under sixteen aspects. Besides that, there is also one category created just for the sewage area. There are three types of the cleaning filtration at the company which are the regular garbage collection, the garbage without toxic substances and the waste water released through the drains. The maintenance of this effluent is carried out by an outsourced contractor.

Inventory division: Inventory division also indicates an excellent result. This area has twenty one aspects with two main categories which are raw materials in process and finished products. Company $\mathrm{A}$ is a company that practices Just In Time (JIT) and supplier Kanban which have become the catalyst for excellence in delivery and receiving of goods. Furthermore, this company always wins the award of excellent supplier for its customers which are Proton Holdings, Toyota Motor Corporation and several other companies.

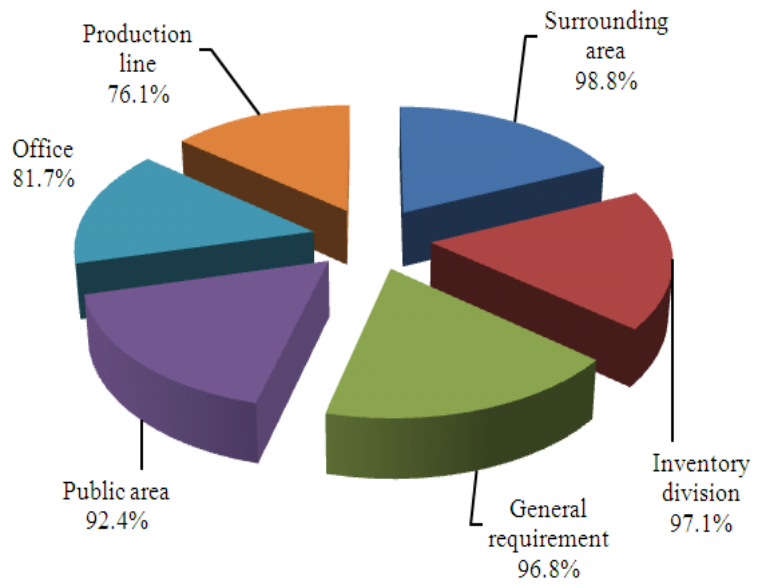

Fig. 1: Percentage value of the $5 \mathrm{~S}$ implementation at Company A 
General requirement: In this study, there are twentyfive aspects concerning education and training, patrol system, current information, reward system and awareness activity, 5S record, discipline of the employees, sound and vibration system, lightning and ventilation and piping system. The Quality Control Circle community (QCC) has become one of their approaches to continue improvement in this company. The structure for conducting continuous improvement is by way of having an improvement facilitator who reviews quality problems together with related teams to find improvement opportunities. To make sure that meetings among the members are held regularly and without any hitches, a space in the production line is provided with complete facilities like a meeting table, chairs and a white board., company A has also introduced a reward system in the form of allowances and incentives for each superb idea in developing the company to an excellent level. Even though the method appears to be simple and obvious, the involvement of employees and management in contributing their ideas and skills for better job execution lead to higher employee satisfaction. The $5 \mathrm{~S}$ module is provided by the company to all its employees in order to show the importance of this activity to the company.

Public area: Rest rooms for guests and employees, prayer room, meeting room, lobby, cafeteria and toilets are the subjects of this assessment. Company A considers the comfort of its visitors and employees as major importance have therefore contributed a lot to this area and $5 \mathrm{~S}$ has become the way of doing business, not only to impress the customers, but to establish effective quality processes as requisites for goods, products and services. Zero emission is one of their targets in the future to support the $0 \%$ air pollution.

Office: It is one of the factors that has a major effect on the management and administration of a company workplace atmosphere. Therefore, the office area becomes one of the primary focuses of attention. Cleaning up and arranging the items in an orderly way is an important activity in order to make sure this area is comfortable and conducive. There are basically, twenty-four aspects in this auditing. These aspects are the condition of the floor, ceiling and walls, arrangement of the tools and equipment and decoration in the office.

Production line: This division indicates the lowest percentage value compared to other divisions. Out of the forty-five aspects that have been observed, labeling the machines at the production line is one of the factors that contribute to the lowest score of this area.

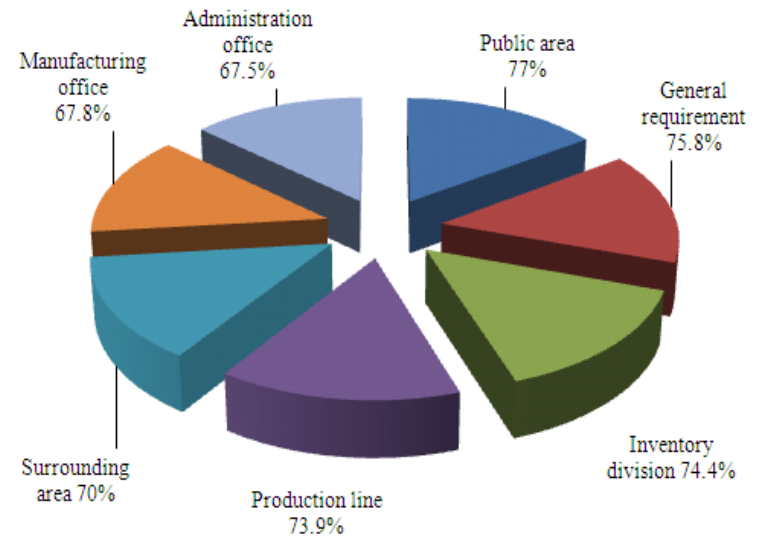

Fig. 2: Percentage value of the $5 \mathrm{~S}$ implementation at Company B

For each type of production, there are four lines that are covered in this observation and these are Radiator Line, Piping Line, MF Condenser Line and the Evaporator Line.

Company B: Figure 2 shows the percentage value of the 5S implementation at company B. According to Fig. 2, the $5 \mathrm{~S}$ implementation at company $\mathrm{B}$ is at moderate level as compared to company A. In can be seen that, both of the administration and manufacturing site at company B indicates the lowest value compared to other divisions.

Public area: The public area indicates the highest score in percentage $(77 \%)$ by taking into account the guest room, prayer room, lobby, canteen and toilets. A supervisor is trusted with the task of monitoring the condition of the stated public areas at all times.

General requirement: Further, general requirement with the percentage of $75.8 \%$ is the second-highest score with stresses on thirty-three important aspects which comprises the fire system, electrical system, lightning, pathways, stairs, emergency aid, activity record 5S member, discipline and awareness of the employees and also the ventilation and piping systems. A change of ownership in company B influenced the implementation of the $5 \mathrm{~S}$ activity. With a new ownership, $5 \mathrm{~S}$ activity was implemented by structuring and establishing a committee known as 5S subcommittee organization. Each $5 \mathrm{~S}$ activity will be recorded in a special column at the production line. Daily, a 5S meeting is held at 7.00 o'clock in the morning involving a representative from each department and a few of employees (particularly the 
foreign employees). Checking the level of cleanliness is also monitored once one month by using a particular check form.

Inventory division: Considering the eighteen aspects for inventory of packaging and printing items, the inventory area percentage is $74.4 \%$. Most of the assessment in this inventory division considers the ergonomic factors in handling the items. It is due to inadequate and ineffective tools and equipment in material handling.

Production line: For the production line, thirty-three aspects are considered in this study and these are involving the condition of the floor, warning signs, transportation, chemical substances used, machines, workbenches, raw materials and finished product storage, material handling and equipment and also emergency plans. Generally, there are three types of production areas in this company and these are printing and extrusion, dry lamination and the bag making division. From the material handling and equipment aspects, the study found that the weaknesses lie in labeling and storage of product.

Surrounding area: Only $70 \%$ is recorded for the surrounding area of this company which stresses on sixteen aspects as those stated by company A. The low score is due to the location of this plant which is very close to a company producing soy bean sauce. Therefore, the surrounding area is untidy, without proper pathways and parking lots.

Manufacturing and administration office: The whole area is separated into two parts one for administration and the other for manufacturing and this is due to limited space of the location of the company. From the observation made, both the manufacturing plant and administration office need more attention from the implementation aspect of the $5 \mathrm{~S}$ activity because the recorded percentage is less than $70 \%$. The aspects considered in this assessment are in the filing and arrangement of the documents, equipment layout and decoration in the office.

\section{DISCUSSION}

Comparison between company A and company B: From the observation carried out, it can be concluded that company $\mathrm{A}$ is standing towards the excellence level as compared to company B. Thus, company B shows weaknesses in several aspects. It is due to the overall percentage of company $\mathrm{B}$ where it only acquires
$72.35 \%$ (good) as compared to company A that obtained an excellent level of $90.48 \%$. The difference in both the percentage happens possibly due to the size, background and the position held in the market by both companies in Malaysia. Although company B started its operation in Malaysia in 1975, it does not seem to have an established background in the management of an industry, unable to strengthen its position in the local market and competing in the global market would be farfetched at this point of time. In comparison to company A, which was launched five years later in 1980 in Malaysia has already become a strong competitor in the global market. This is probably due to the fact that the mother company had been already solidly established in Japan since the year 1949. Company $\mathrm{A}$ is also probably set up as a partner of the renowned Toyota Motor Corporation with being a very distinguished upholder in the area of quality. Obviously, a strategic partner with a strong position also assists a company to stabilize itself in the industry.

Apart from that, the type of production also plays an important role to determine the level of the industry involved. For example, with the moderate size of company $\mathrm{B}$ that only manufacture products based upon packaging, it has lacked in addressing issues related to environmental awareness due to being a factory with less complicated processing amenities. On the other hand, company A manufactures electronic and mechanical based products which obviously require the most profound scrutiny in their production process due to the environment factors like the temperature, pressure and emission of gases, it would therefore be compulsory for this company to have installations to prevent environmental degradation.

\section{Suggestions:}

Suggestion of $5 \mathrm{~S}$ Implementation at company A: This organization did not have any objections or raised any issues on the practice of the $5 \mathrm{~S}$ activity and have used it consistently. On the implementation of the $5 \mathrm{~S}$ activity, the company's overall score is 90.48 percent, which is an excellent level. However, several critical problems have been observed in the duration of this study by the researcher and therefore suggest an improvement proposal as outlined below:

- Taking action on reducing the sound and vibration levels of the decibel to an appropriate level in order to decrease the noise as generally required by regulations. Apart from that, another solution to the noise problem is for the company to install the ear muff system at places where the noise frequency is very high. It is also essential for a company to 
evaluate the noise level especially before installing any new machines for processing or when carrying out modifications to an existing production process or even when purchasing and installing new equipment

- Maintenance of the piping system should be carried out frequently. To ensure the piping system is in good working condition, maintenance personnel should be made responsible to check the system on a planned schedule

- The arrangement of the equipment is seen to be in an unsatisfactory condition. Fixing the right sized study benches and more drawers will help to reduce the clutter as well as improve the ergonomics of the workplace

- All machines need to be labeled and study pathways should be marked correctly and clearly in color. Both writing and coding systems will assist in reducing the misuse and abuse of machines and prevent accidents at the workplace

- Machines need to be thoroughly cleaned periodically otherwise problems concerning the cleanliness of the machines would arise due to oil and chemicals settling via the installation inhale fluid system of the machine which is the support mechanism in the machine itself to suck up the oil that spills during processing

- The distance marker element and a warning system sound should be installed in helping to improve the capacity of the material handling and the transportation system in the workplace. Besides that, fire drills need to be carried out at least three times per year and the latest and most effective emergency plan should be displayed at each exit. Frequent meetings and a rapport should be established with the Department of Organizational Safety and Health (DOSH). These will assist the company in dealing with the safety and health of their company efficiently

Suggestion of $5 \mathrm{~S}$ Implementation at company B: Although this company has been established for the last three decades, it has only been practicing the $5 \mathrm{~S}$ activity at its workplace for the five years consistently but however it has been observed that the $5 \mathrm{~S}$ practice is not conducted formally. The practice of the $5 \mathrm{~S}$ activity needs to be improved due to the fact the overall percentage is only $72.35 \%$ which ranks it as only good. Several critical problems have been observed during this study and therefore an improvement proposal is recommended by the researcher as follows:

- The company should establish a benchmarking system with other successful organizations and make references from time to time with any member of Quality Control Bodies which will provide aid to this organization in realizing its mission and vision

- The 5S form is incomplete as it does not have a space on examination and evaluation to categorize this company. This can be solved by using print photographing to display images that need the attention of the observer

- In order to make the $5 \mathrm{~S}$ study the top management has to give its full support to practice this activity in their company. But it is observed that the top management of this company is not supporting the $5 \mathrm{~S}$ practice and the reason given by them is the amount of the time and money that would be required to implement the proposed activities in the $5 \mathrm{~S}$. In order to make the top management aware of the effectiveness of the $5 \mathrm{~S}$ they have to be shown the performance indicators relating to the costs involved, sales, profits and product quality of this approach. For example, by comparing the quality of production by a machine before and after the implementation of $5 \mathrm{~S}$ activity

- This company has limited space and is a closed building. Therefore the ventilation system in this company is in a critical condition. The odor of the printing materials is of course hazardous to the health of the employees especially those in the production line. Therefore Company B should take into account this problem by installing or mounting vacuum suction equipment. Besides that, the management should fix proper air conditioners or efficient fans in the production line area

- The right amount of lights and lighting intensity should be checked to suit the task especially at the study areas where checking of the quality of the product is carried out. To make sure the lighting level is in accordance with the standards required by regulations the organization should install a photometer in a specific area to find out and monitor the index of the light intensity

- The labeling system is found to be unsatisfactory especially in the store. The labeling of goods should also be monitored as it is incomplete and not enough. This matter needs to be seriously looked into to avoid confusion and technical problems that could happen in future. There should also be a coding system to label documents and files

- The inventory division which involves storage of the printing material and packaging needs to be frequently monitored. Besides, the ergonomics of 
the layout and furniture, user friendly equipment such as ladders and a forklift to pick and store the items should be provided by the company to assist the employees

- A flow chart of the storage for both raw and finished materials needs to be presented and updated, so the employees will place the items at the right place

- Cleanliness and health levels should be ensured through the wearing of badges by some appointed employees. These badges will act as detectors by becoming discolored if there is any toxic substance released at any level

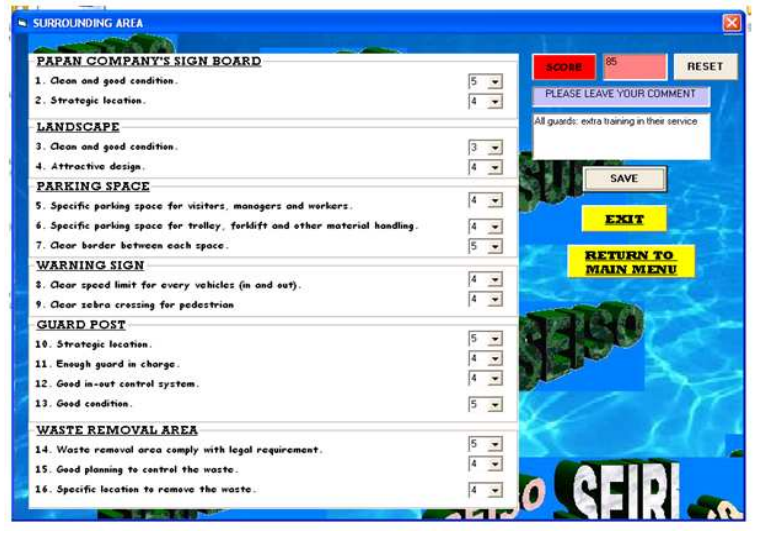

Fig. 3: Checklist's sample

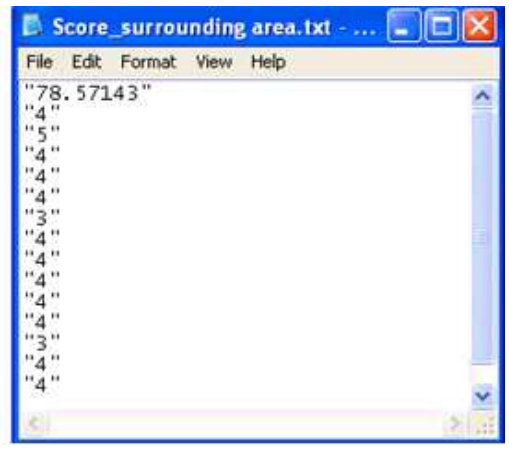

Fig. 4: Recorded score

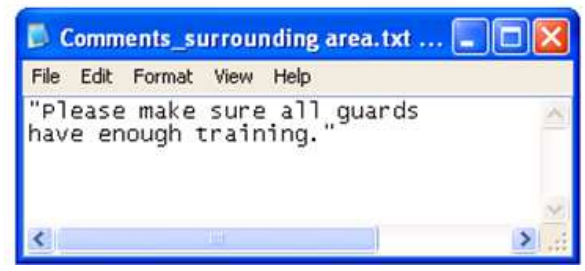

Fig. 5: Recorded comment
Improvement on 5S Checklist by using Visual Basic: In order to reduce calculation time via a manual checklist, the author have developed 5S Checklist by using Visual Basic. In addition, this tool can help to enhance 5S implementation at the company through the systematic checklist. Generally, this tool covers all aspects that are observed in the manual audit. All the pages are connected via some command that has its own programming code. At the same time, the assessors also can put their comments as shown in Fig. 3. Key features of this tool are:

- User friendly

- User can review recorded comment and score

- All recorded comment and score can be emailed, printed either in hard coy and soft copy

- Offer interesting key features, which is more graphical common buttons compared to manual checklist

The user also able to save and record the score and leave their comment by clicking the score and save button. Figure 4 and 5 shows a recorded score and recorded comment.

\section{CONCLUSION}

The outcome of the surveys at both companies demonstrates clearly that the $5 \mathrm{~S}$ practice is seen as an effective technique that can improve housekeeping, environmental performance, health and safety standards in an integrated holistic way. It can be observed that there are some similarities in the approaches adopted by the companies. It can be regarded as the promotion of the $5 \mathrm{~S}$ activity amongst the staff and as a training method for the staff.

The survey demonstrates, however, that there are obstacles in the effective implementation of the 5S for any improvement purpose. The most significant barriers identified are related to lack of communication and gap between the top management and shop floor employees and also the lack of training and consciousness of this activity amongst the staff. Poor communication will influence the poor results in managing the resources i.e. time, budget and materials with resultant lowered morale and motivation amongst employees. As supported by Gapp et al. (2008), some critical decisions of $5 \mathrm{~S}$ activity, especially which related to budget and time performance must have management approval and support.

As suggested by Ho (1999b), training is the 5S's key of success. Without proper training, the employees haven't captured the $5 \mathrm{~S}$ implementation properly and 
are not able to standardize the 5S activity. Besides, the top management is the main player for ensure that the $5 \mathrm{~S}$ activity run as planned. The authors agreed that the resistance to change is one issue which organization should pay attention to when implementing the $5 \mathrm{~S}$ practices, especially those small organizations with a niche or practicing business-to-business nature, are comfortable with their current achievement. The employees are satisfied with the amount of study being performed, the profits released and the perception that the customers are satisfied. Thus, the full benefits of the $5 \mathrm{~S}$ cannot be experienced in the business sector until all the obstacles associated with implementation of the technique are recognized, fully understood and addressed.

Therefore, continuous assessment in both companies is believed one of the key drivers to changing the culture of the organization. This continuous assessment should be focused on the progress and improvement based on all input from this study. Having a differentiation and comparison (beforeand-after) will be beneficial when attempting to finalize an implementation of the $5 \mathrm{~S}$ activity suitable for the company. In terms of developing the package using the software, having the details of the assessors, a comment page, suggestion for improvement and analysis of the data are good applications for the next study.

\section{REFERENCES}

Gapp, R., R. Fisher and K. Kobayashi, 2008. Implementing $5 \mathrm{~S}$ within a Japanese context: An integrated management system. Manage. Dec., 46: 565-579. DOI: 10.1108/00251740810865067

Hamzah, A. and S. Ho, 1994. TQM training for small and medium industries in Malaysia. Train. Qual., 2: 27-35. DOI: 10.1108/09684879410064365

Ho, S.K.M., 1997. Workplace learning: The 5S way. J. Workplace Learn., 19: 185-191. $10.1108 / 13665629710180375$
Ho, S.K.M., 1999a. Japanese 5-S-where TQM begins. TQM Mag., 11: 311-320. DOI: $10.1108 / 09544789910282345$

Ho, S.K.M., 1999b. The 5S auditing. Manage. Audit. J., 14: 294-301.

Ho, S.K., S. Cicmil and C.K. Fung, 1995. The Japanese 5-S practice and TQM training. Train. Qual., 3: 19-24. DOI: 10.1108/09684879510098222

Ho, S.K.M. and C.K.H. Fung, 1994. Developing a TQM excellence model. TQM Mag., 6: 24-30. DOI: $10.1108 / 09544789410073612$

Idris, M.A., W. McEwan and N. Belavendram, 1997. A TQM implementation model for small and medium sized manufacturing firms. Proceeding of The $2 \mathrm{nd}$ International Conference on ISO 9000 and TQM, Apr. 2-4, The Luton Business School, University of Luton, pp: 399-404.

Khanna, V.K., 2009. 5 "S" and TQM status in Indian organizations. TQM J., 21: 486-501. DOI: 10.1108/17542730910983407

O'hEocha, M., 2000. A study of the influence of company culture, communications and employee attitudes on the use of $5 \mathrm{Ss}$ for environmental management at Cooke Brothers Ltd. TQM Mag., 12: 321-330. DOI: 10.1108/09544780010341923

Pheng, L.S., 2001. Towards TQM-integrating Japanese 5-S principles with ISO 9001:2000 requirements. TQM Mag., 13: 334-341. DOI: 10.1108/EUM0000000005859

Sui-Pheng, L. and S.D. Khoo, 2001. Team performance management: Enhancement through Japanese 5-S principles. Team Perform. Manage., 17: 105-111. DOI: $10.1108 / 13527590110411000$

Warwood, S.J. and G. Knowles, 2004. An investigation into Japanese 5-S practice in UK industry. TQM Mag., 16 : 374-353. $10.1108 / 09544780410551287$ 